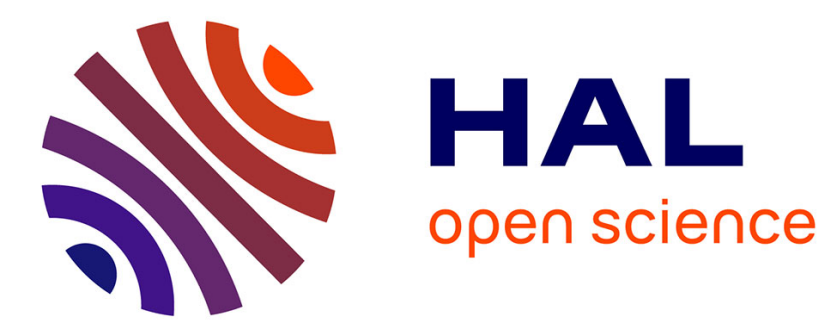

\title{
Penning ionization of argon by metastable helium atoms : a study of the energy and angular distributions of the ejected electrons \\ F. Tuffin, G. Le Coz, J. Peresse
}

\section{- To cite this version:}

F. Tuffin, G. Le Coz, J. Peresse. Penning ionization of argon by metastable helium atoms : a study of the energy and angular distributions of the ejected electrons. Journal de Physique Lettres, 1979, 40 (13), pp.271-275. 10.1051/jphyslet:019790040013027100 \& jpa-00231623

\section{HAL Id: jpa-00231623 \\ https://hal.science/jpa-00231623}

Submitted on 1 Jan 1979

HAL is a multi-disciplinary open access archive for the deposit and dissemination of scientific research documents, whether they are published or not. The documents may come from teaching and research institutions in France or abroad, or from public or private research centers.
L'archive ouverte pluridisciplinaire HAL, est destinée au dépôt et à la diffusion de documents scientifiques de niveau recherche, publiés ou non, émanant des établissements d'enseignement et de recherche français ou étrangers, des laboratoires publics ou privés. 


\title{
Penning ionization of argon by metastable helium atoms : a study of the energy and angular distributions of the ejected electrons
}

\author{
F. Tuffin, G. Le Coz and J. Peresse \\ Laboratoire de Collisions Electroniques et Atomiques $\left({ }^{*}\right)$, \\ Université de Bretagne Occidentale, UER Scientifiques, 6, avenue Le Gorgeu, 29283 Brest Cedex, France
}

(Reçu le 19 mars 1979, accepté le 8 mai 1979)

Résumé. - L'étude de l'ionisation Penning de l'argon par l'hélium dans les états métastables $2{ }^{1} \mathrm{~S}$ et $2{ }^{3} \mathrm{~S}$ est réalisée. Les spectres en énergie des électrons éjectés sont obtenus pour une série d'angles dans le domaine $30^{\circ}$ à $90^{\circ}$.

\begin{abstract}
Experimental measurements are reported for the Penning ionization of an argon target by impact of metastable helium atoms. The energy spectra of the ejected electrons are obtained at a series of angles in the range $30^{\circ}$ to $90^{\circ}$, and the intensities due to the different metastable states compared.
\end{abstract}

1. Introduction. - Penning ionization results from the interaction between a projectile atom in a metastable state $\mathrm{X}^{*}$ and a target atom or molecule $\mathrm{Y}$, and is essentially a process analogous to autoionization. As the projectile approaches the target a compound molecule is formed, in an excited state, which is degenerate in energy with the continuum based on the molecular ion $\mathrm{XY}^{+}$. Decay into this continuum occurs and the deexcited projectile $X$ and the ion $\mathrm{Y}^{+}$separate :

$$
\mathrm{X}^{*}+\mathrm{Y} \stackrel{\boldsymbol{E}_{\mathrm{c}}}{\mathrm{X}}+\mathrm{Y}^{+}+\mathrm{e}^{-} \text {. }
$$

The process may occur for any initial relative kinetic energy $E_{\mathrm{c}}(\infty)$ of the projectile and target, provided that the energy available from deexcitation of the metastable atom is at least as large as the ionization potential of the target. Otherwise, the alternative process of associative ionization occurs, with formation of a stable compound molecule $\mathrm{XY}^{+}$

$$
\mathrm{X}^{*}+\mathrm{Y} \stackrel{\boldsymbol{E}_{\mathrm{c}}}{\mathrm{X}} \mathrm{Y}^{+}+\mathrm{e}^{-} \text {. }
$$

Both experimental and theoretical studies of Penning ionization over the last few years (V. Cermak [1], Hotop and Niehaus [2] and [3], Brion et al. [4], Coleman et al. [5], Miller [6], Miller et al. [7], A. P. Hickman et al. [8], J. C. Bellum et al. [9]) have interpreted the process in terms of a model employing the BornOppenheimer approximation and making use of the

(*) Equipe de recherche associée au CNRS no 256. potential curves $V^{*}(R)$ for the system $\mathrm{X}^{*}+\mathrm{Y}$ in the entrance channel and $V^{+}(R)$ for the system $\mathrm{X}+\mathrm{Y}^{+}$. The potential curves $V^{+}\left(R, E_{\mathrm{d}}\right)$ for the system $\mathrm{X}+\mathrm{Y}^{+}+\mathrm{e}^{-}$in the exit channel with an ejected electron energy of $E_{\mathrm{d}}$, are assumed to have an identical form to $V^{+}(R)$, and are simply displaced globally by an additive factor of $E_{\mathrm{d}}$. Thus at any particular internuclear distance $R=R_{1}$, one of this family of curves will cross the curve $V^{*}(R)$. The transition may take place at any distance $R_{1}$ greater than the classical turning point $R_{0}$ (Fig. 1), which is defined as the projectile-target distance for which the relative kinetic energy $E_{\mathrm{c}}(R)$ is zero, where

$$
E_{\mathrm{c}}(R)=E_{\mathrm{c}}(\infty)+V^{*}(\infty)-V^{*}(R) .
$$

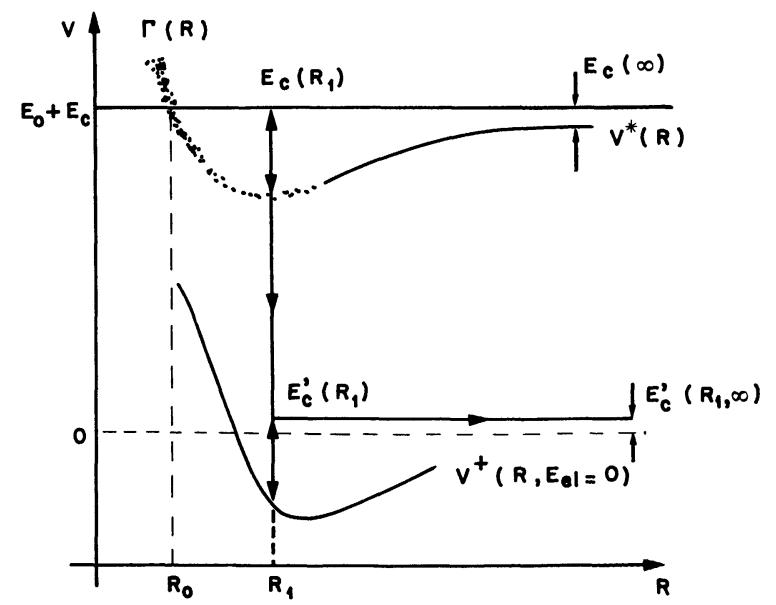

Fig. 1. - Potential curve model of Penning ionization. 
The final relative kinetic energy $E_{\mathrm{c}}^{\prime}\left(R_{1}, \infty\right)$ depends on the internuclear distance at which the transition occurs, and

$$
E_{\mathrm{c}}^{\prime}\left(R, R_{1}\right)=E_{\mathrm{c}}\left(R_{1}, \infty\right)+V^{+}(\infty)-V^{+}(R) .
$$

If we assume that the relative kinetic energy is conserved at the moment of transition, we may write :

$$
\begin{aligned}
E_{\mathrm{d}}\left(R_{1}\right)=V^{*}\left(R_{1}\right)-V^{+}\left(R_{1}\right)=E_{0} & +E_{\mathrm{c}}(\infty)- \\
& -E_{\mathrm{c}}^{\prime}\left(R_{1}, \infty\right)
\end{aligned}
$$

where

$$
E_{0}=V^{*}(\infty)-V^{+}(\infty)
$$

Thus the energy distribution of the ejected electrons, which we have studied experimentally, depends directly on the shape of the two potentials. In addition to these it is necessary to estimate the probability $P\left(R_{1}\right)$ of transition at a particular radius, which is related to the decay width $\Gamma\left(R_{1}\right)$ of the quasi-molecule $\mathrm{X}^{*} \mathrm{Y}$ :

$$
P\left(R_{1}\right)=\Gamma\left(R_{1}\right) / \hbar \text {. }
$$

2. Experimental apparatus. - This is presented schematically in figure 2 . A jet of helium with angular spread of about $5^{\circ}$ is obtained by means of a $50 \%$ transparency multicapillary array and is excited by a horizontal 30 to $40 \mathrm{eV}$ electron beam of $1 \mathrm{~mA}$ intensity, over a distance of $1 \mathrm{~cm}$. The different charged particles present in the resulting beam are eliminated by means of a set of condensing electrodes; the beam then travels a certain distance (to permit deexcitation to the ground state of all but the metastable levels) before entering a large collision chamber. There it intersects a vertical beam of the target gas (argon in the case of the present article) and the electrons resulting from Penning ionization are detected by a channeltron, after energy selection by means of a system of accelerating focussing and decelerating electrostatic lenses, followed by a $127^{\circ}$ cylindrical electrostatic analyser. They are counted by means of a multichannel analyser functioning in the multiscalar mode. The detection system accepts electrons in only a small solid angle, and is rotatable coaxially with the target gas beam, through an angle of $90^{\circ}$ with respect to the helium beam direction.

All surfaces in the detection system are gold-coated in order to minimize voltage fluctuations and contact potentials. In view of the high background noise levels which occur if the metastable atoms hit a metal surface in the vicinity of the selector, special precautions have been taken with the primary collimation of the helium beam and the choice of window diameter for entry into the collision chamber.

In addition to the metastable atoms in the helium beam, there are also present photons of energy $584 \AA$, resulting from the decay of the helium levels. Thus we observe simultaneously with the ejected electron spectrum due to Penning ionization, a spectrum due to photoionization. Comparison of these two spectra is of considerable help in interpreting the experimental results, especially in the case of a molecular target gas (experiments with a molecular nitrogen target will form the subject of a future article).

3. Experimental results. - A typical ejected electron spectrum, obtained after an accumulation time of the order of ten hours, is presented in figure 3.

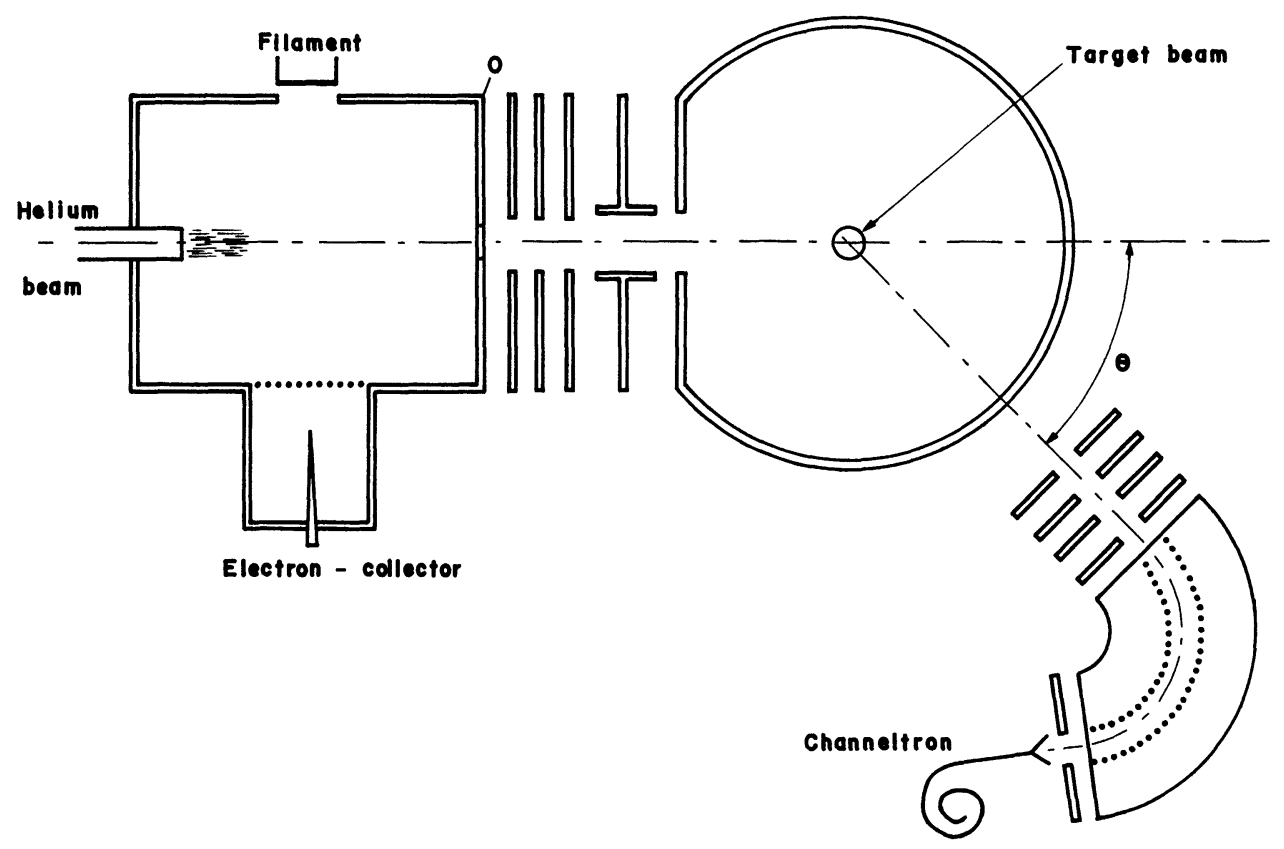

Schematic diagram of the apparatus.

Fig. 2. - Schematic drawing of the main parts of the apparatus. 
There are two possible states of the $\mathrm{Ar}^{+}$ion $\left({ }^{2} \mathrm{P}_{3 / 2}\right.$ and $\left.{ }^{2} \mathrm{P}_{1 / 2}\right)$; thus we find a total of six structures. The two central peaks, which have a signal to noise ratio of 50 , result from the $2{ }^{1} \mathrm{~S}$ metastable state. Those to the right result from the $2{ }^{3} \mathrm{~S}$ metastable state, and those to the left from photoionization.

From spectroscopic measurements the separation of the ${ }^{2} \mathrm{P}_{3 / 2}$ and ${ }^{2} \mathrm{P}_{1 / 2}$ levels of $\mathrm{Ar}^{+}$is known to be $178 \mathrm{meV}$; it is also possible to calculate that the photoionization peaks in our experiment must be centred on energies of $5.458 \mathrm{eV}$ and $5.280 \mathrm{eV}$ respectively. We may thus obtain an accurate calibration of our energy scale. Furthermore, the profile of these peaks is necessarily that of the experimental apparatus : it is a gaussian of half-width $50 \mathrm{meV}$.

It is found experimentally that the structures due to Penning ionization are centred on energies which are shifted by $\Delta E$ from the values which would be expected from taking a simple difference between the excitation energy of the metastable levels and the ionization potential of the target. The shift appears to similar for the structures corresponding to the $2{ }^{3} \mathrm{~S}$ metastable and those corresponding to the $2{ }^{1} \mathrm{~S}$ metastable states. In table I we compare the shifts obtained in our
Table I. - Energy shift $\Delta E$ of the peaks due to Penning ionization.

\begin{tabular}{lc}
\multicolumn{1}{c}{ Author } & $\Delta E$ \\
Brion et al. & $\Delta E=+44 \mathrm{meV}$ \\
Hotop et al. & $\Delta E=+46 \mathrm{meV}$ \\
Cermak et al. & $\Delta E=+50 \mathrm{meV}$ \\
Present work & $\Delta E=+42 \mathrm{meV}$
\end{tabular}

experiments to those of other workers. The observed widths of the peaks due to the $2{ }^{1} \mathrm{~S}$ and $2{ }^{3} \mathrm{~S}$ metastable states are of the order of $85 \mathrm{meV}$ and $125 \mathrm{meV}$ respectively, suggesting that the real widths, after deconvolution with the apparatus profile, are of the order of 35 and $75 \mathrm{meV}$ respectively in good agreement with the results of Hotop and Niehaus (1969). We may conclude that the energy shift is an effect due principally to the structure of the target atom, and not to that of the projectile, and that the well in the potential curve for the system $\mathrm{He}\left(2{ }^{3} \mathrm{~S}\right)+\mathrm{Ar}$ is considerably deeper than that for the system $\mathrm{He}\left({ }^{1} \mathrm{~S}\right)+\mathrm{Ar}$. This is in good agreement with the theoretical work of W. H. Miller and H. F. Shaeffer [10].
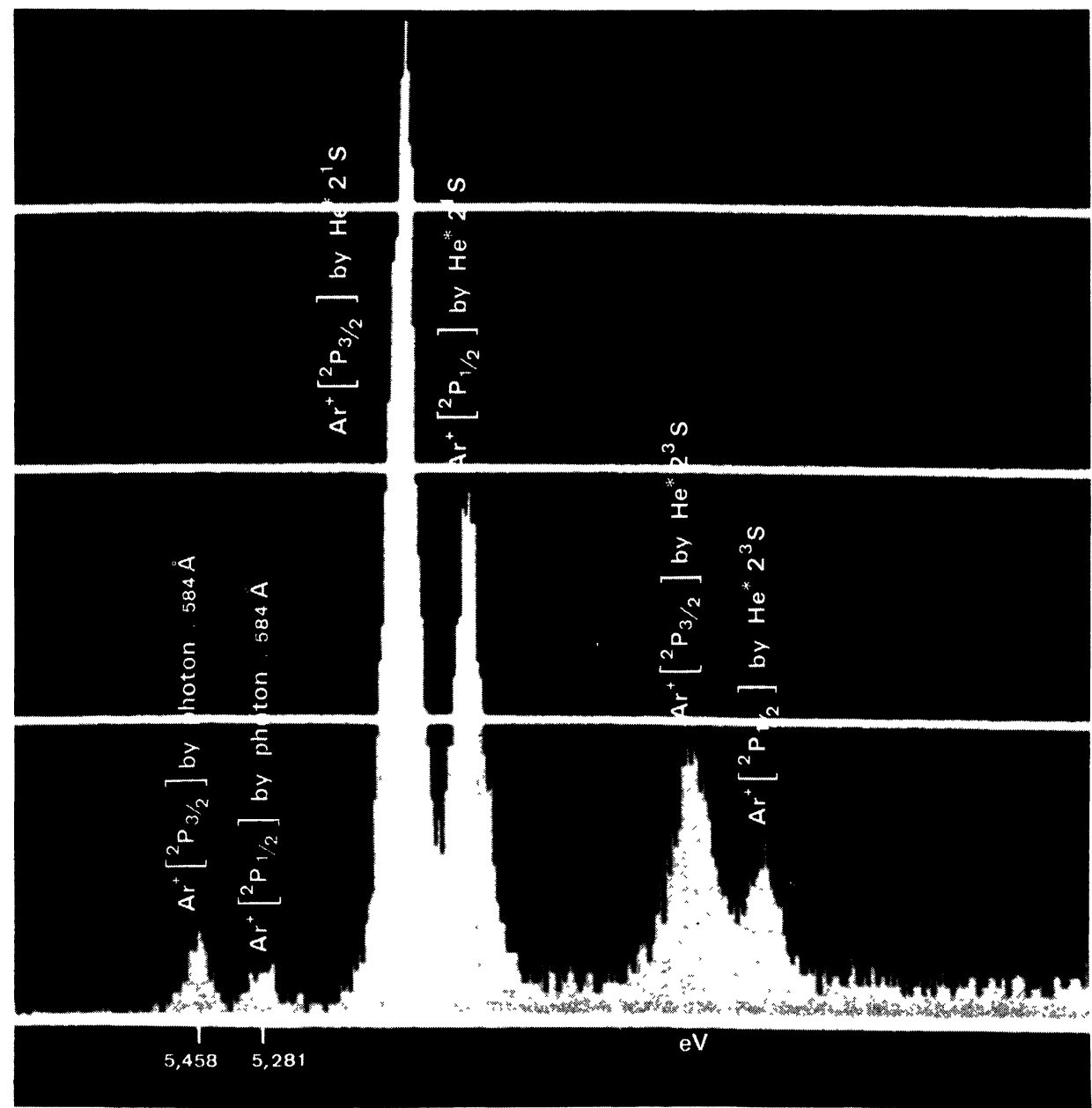

Penning ionization of argon.

Fig. 3. - Penning electron spectra of argon. 
In table II, we compare the relative intensities of different peaks, taken at an ejected electron angle of $90^{\circ}$.

Table II. - Intensity ratio of the structures : $\mathrm{Ar}^{+}\left({ }^{2} \mathrm{P}_{3 / 2}\right) / \mathrm{Ar}^{+}\left({ }^{2} \mathrm{P}_{1 / 2}\right)$ corresponding to Penning ionization by metastable $2{ }^{1} \mathrm{~S}$ and $2{ }^{3} \mathrm{~S}$ and to photoionization.

$\begin{array}{lccc}\text { Author } & \text { Photoionization } & 2{ }^{1} \mathrm{~S} & 2{ }^{3} \mathrm{~S} \\ \text { Brion } \text { et al. } & - & - & - \\ \text { Cermak } \text { et al. } & 1.94 & 2.00 & 1.94 \\ \text { Samson } \text { et al. } & 1.98 & 1.82 & 2.04 \\ \text { Present work } & 2.00 & 2.04 & 1.92\end{array}$

In their experiments of 1969, Hotop and Niehaus used a retarding field analyser, collecting electrons at an angle of $90^{\circ}$ to the helium beam direction. They studied the Penning ionization profiles in detail, and reported structure on the high-energy side on the peaks for $\mathrm{He}\left({ }^{3} \mathrm{~S}\right)$ on $\mathrm{Ar}$ and Xe targets. Later studies by Hotop and Hubler [11] have shown that under certain experimental conditions, a retarding field analyser can cause the appearance of non-physical structure. In fact neither Brion et al. [4] nor V. Cermak and Ozenne [12] were able to observe the structure; both experiments used a $127^{\circ}$ analyser of the same type as we have adopted for our present experiments.

Hotop and Niehaus [13] and Ebding and Niehaus [14] use a similar technique, but employ two $127^{\circ}$ selectors, one at $90^{\circ}$ to the helium beam direction, and the other rotatable from $20^{\circ}$ to $160^{\circ}$ with respect to it. Apart from that reported in the present article, theirs is the only apparatus of which we know in which the analyser can be rotated. There are two main problems with this type of apparatus : the first is that at small angles the metastable atom beam enters the selector, causing a large increase in background noise; the second is that, unless large signals are employed, with a corresponding loss of resolution, each angle studied requires several hours. The second selector at a fixed angle, in the experiments of Niehaus and collaborators, enables them to eliminate eventual errors due to experimental drift, in relating spectra taken at different angles.

In our apparatus, we have no second, fixed angle selector, and so are confident only in presenting a ratio, as a function of ejected electron angle, of Penning ionization due to the helium $2{ }^{1} \mathrm{~S}$ and $2{ }^{3} \mathrm{~S}$ metastable respectively. We are also limited in angular range $\left(30^{\circ}\right.$ to $\left.90^{\circ}\right)$. However, we have an energy resolution, and a background noise which is completely flat as a function of energy. Our spectra are considerably cleaner and better resolved than that published by Hotop and Niehaus [13] in their initial letter. Unfortunately, it is not clear in the publication

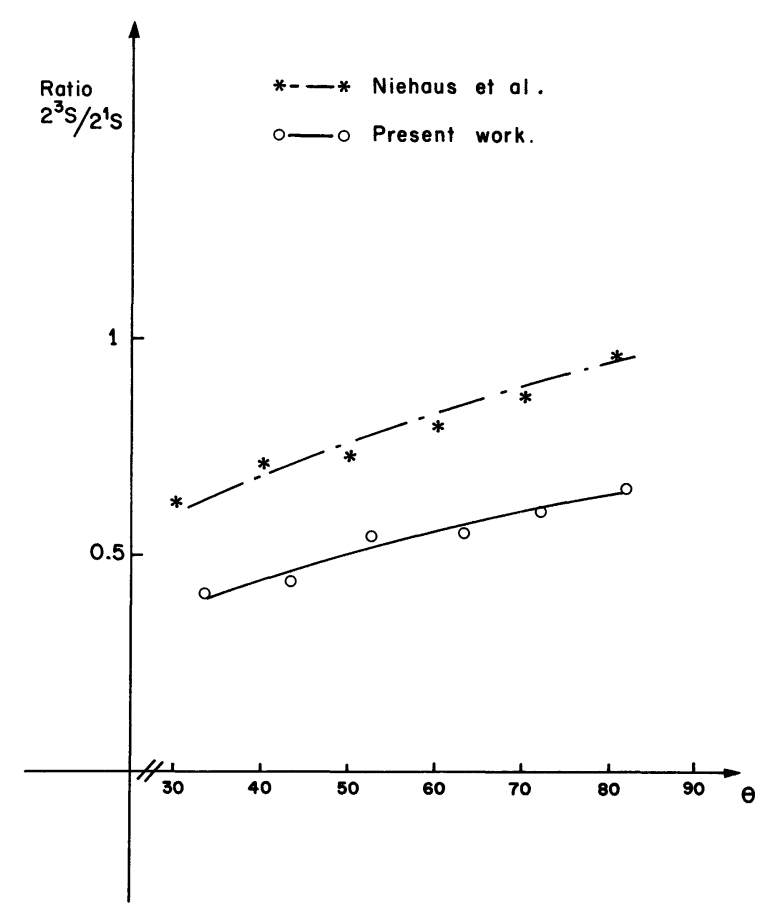

Angular distribution of ejected electrons.

Fig. 4. - Angular dependence of the intensity ratio of the structures in the ejected electron spectra corresponding respectively to Penning ionization by the $\mathrm{He} 2{ }^{3} \mathrm{~S}$ and $2{ }^{1} \mathrm{~S}$ metastables. * Niehaus et al. curve corresponding to a mixture of $\mathrm{Ar}^{+}{ }^{2} \mathrm{P}_{1 / 2}$ and $\mathrm{Ar}^{+}{ }^{2} \mathrm{P}_{3 / 2}$ states. $\mathrm{O} \longrightarrow \mathrm{O}$ Present work. This curve corresponds

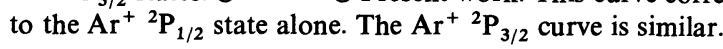

of Ebding and Niehaus [14] whether the resolution was improved in the subsequent more complete experiments. It is interesting to note that we see no structure whatsoever in our peaks. In figure 4 we present our results for the ratio of ionization by $2{ }^{3} \mathrm{~S}$ and $2{ }^{1} \mathrm{~S}$ as a function of angle, and compare with the results of Niehaus and collaborators. It is important to note that Ebding and Niehaus give results for the $2{ }^{1} \mathrm{~S}$ and $2{ }^{3} \mathrm{~S}$ individually, both normalized to unity at $90^{\circ}$. The ratio $2{ }^{3} \mathrm{~S} / 2{ }^{1} \mathrm{~S}$ which we have inferred from their published curves is thus also normalized to unity at $90^{\circ}$. Their results concern the sum of the peaks due to the two residual ion states. Our own results are for the ratio of peak heights taken directly from our spectra, after the background noise has been subtracted out. We are also able to present results separately for the two states of the residual ion. It can be seen that we confirm completely the observations of Niehaus and collaborators, both in respect of the angular behaviour of the ratio $2^{3} \mathrm{~S} / 2{ }^{1} \mathrm{~S}$ and of its independence of the state of the residual ion.

Acknowledgments. - The authors are indebted to Dr. R. Tweed for many helpful comments. 


\section{References}

[1] Cermak, V., J. Chem. Phys. 44 (1966) 3781.

[2] Hotop, H. and Niehaus, A., Z. Phys. 228 (1969) 68.

[3] Hotop, H. and Niehaus, A., Z. Phys. 238 (1970) 432.

[4] Brion, C. E., McDowell, C. A. and Stewart, W. B., J. Electron. Spectrosc. Relat. Phenom. 1 (1972/73) 113.

[5] Coleman, M. L., Hammond, R., Dubrin, J. W., Chem. Phys. Lett. 19 (1973) 271.

[6] Miller, W. H., J. Chem. Phys. 52 (1970) 3563.

[7] Miller, W. H., Slocomb, C. A. and Schaefer III, H. F., $J$. Chem. Phys. 56 (1972) 1347.
[8] Hickman, A. P. and Morgner, H., J. Phys. B 9 (1976) 1765.

[9] Bellum, J. C. and DA. Micha, Phys. Rev. A 18 (1978) 1435.

[10] Miller, W. H. and Schaeffer III, A. F., J. Chem. Phys. 53 (1970) 1421.

[11] Нотор, H. and Hubler, G., J. Electron. Spectrosc. Relat. Phenom. 11 (1977) 101

[12] Cermak, V. and Ozenne, J. B., Int. J. Mass. Spectrom. Ion Phys. 7 (1971) 399.

[13] Hotop, H. and Niehaus, A., Chem. Phys. Lett. 8 (1971) 497.

[14] Ebding, T. and Niehaus, H., Z. Phys. 270 (1974) 43.

[15] Samson, J. A. R. and Cairns, R. B., Phys. Rev. 173 (1968) 80. 